\title{
Effect of Blending Ratio of Steel Can Pellets without Cap on Mechanical Properties of Spheroidal Graphite Cast Iron*1
}

\author{
Katsumi Koike ${ }^{1, * 2}$ and Satoshi Akita ${ }^{2}$ \\ ${ }^{1}$ Material Technology Department, Industrial Research Institute of Tochigi Prefecture, Utsunomiya 321-3224, Japan \\ ${ }^{2}$ Development Department, Kusakabe Maritime Engineering Co., Ltd., Kobe 651-0083, Japan
}

The authors attempted to use steel can pellets after removing the Al-Mg alloy of can's cap part using differences in the melting point of steel and Al, for melt-casting spheroidal graphite cast iron in a high-frequency furnace. Then, they examined differences in the mechanical properties such as tensile strength and hardness and the microstructure of cast test specimens. Although tensile strength and hardness increased with an increase in the blending ratio of steel can pellets as an iron source, the specimen made by melting only steel can pellets as an iron source showed a remarkable drop in elongation. However, since abnormality in the microstructure was not recognized in all tested specimens, it was judged that material properties were not deteriorated when iron scrap was replaced with steel can pellets within the blending ratio of up to $60 \%$. Judging from these test results, it is suggested that steel can pellets used in this experiment can be utilized as a raw material for spheroidal graphite cast iron in the blending ratio up to $60 \%$. [doi:10.2320/matertrans.F-M2009805]

(Received January 5, 2009; Accepted March 2, 2009; Published May 25, 2009)

Keywords: steel can scrap, cast iron, spheroidal graphite, raw material

\section{Introduction}

Used steel cans have been utilized mainly by blast furnace steel makers and arc furnace steel makers, ${ }^{1)}$ since the can's body part is excellent steel material and the Al-Mg alloy of can's cap part works as a deoxidizing agent. However, since the use of a large quantity of used steel cans leaves $\mathrm{Al}$ in the product, the use by blending to conventional scraps is a present common practice. In particular, foundries using a melting process with little refining effects tend to strongly abhor the entry of $\mathrm{Al}$ as a defect prevention measures. Since the Al-Mg alloy of can's cap part hindered the recycling of steel cans, several methods to remove the Al-Mg alloy have been contrived.

One method is to apply shredder treatment to used steel cans for removing the $\mathrm{Al}-\mathrm{Mg}$ to some extent through magnetic separation. Another method is to remove the Al$\mathrm{Mg}$ alloy by utilizing differences in melting point of steel and $\mathrm{Al}$. The former has a merit such as low treatment cost, but this method is impossible to completely separate steel and $\mathrm{Al}-\mathrm{Mg}$ alloy. The latter can separate steel and Al-Mg better than the former does, but it has a disadvantage of high investment cost for treating facilities. In consideration of the qualitative improvement of steel can scrap, the latter will become the mainstream in the future.

This research attempted an experiment to use steel can pellets that are obtained by removing the Al-Mg alloy of can's cap part using differences in the melting point of steel and $\mathrm{Al}$, for casting spheroidal graphite cast iron. This paper reports experimental result of residual element quantities, tensile strength, hardness and microstructure of test specimens cast from steel can pellets.

\footnotetext{
${ }^{* 1}$ This Paper was Originally Published in Japanese in J.JFS 80 (2008) 619-623.

*2Passed away in 2009.
}

\section{Experimental Procedure}

Target chemical composition was as follows: $\mathrm{C}=3.8$ mass $\%$ (hereinafter, referred to as \%), $\mathrm{Si}=2.5 \%$, $\mathrm{Mn}=0.3 \%$. Using pig iron and steel can pellets (hereinafter, referred to as pellets) as major iron sources, melting operation was performed with a high-frequency furnace. As the standard molten metal that did not use pellets, $9 \mathrm{~kg}$ of pig iron were molten and were followed by component adjustment. Within $9 \mathrm{~kg}$ of pig iron, the weight ratio of $10,20,40$, 60 and $100 \%$ were replaced with pellets and the mixtures were molten. For component adjustment, electrolytic iron, carburizer, electrolytic $\mathrm{Mn}$ and $\mathrm{Fe}-75 \% \mathrm{Si}$ alloy were added.

In melting, pig iron was first molten, and pellets and electrolytic iron were added. When carburization was necessary, pellets and carburizer were alternately added. Electrolytic $\mathrm{Mn}$ and $\mathrm{Fe}-75 \% \mathrm{Si}$ alloy were added at $1723 \mathrm{~K}$, and after slag removal. In advance, $\mathrm{Fe}-45 \% \mathrm{Si}-6.5 \% \mathrm{Mg}$ alloy and $\mathrm{Fe}-75 \% \mathrm{Si}$ (Inoculant) were added into a ladle as a sandwich method for spheroidizing treatment. Then, the molten metal was tapped into the ladle for spheroidizing treatment at $1823 \mathrm{~K}$. For temperature measurement, a $\phi 0.3 \mathrm{R}-$ type thermocouple protected with a quartz tube was inserted into the molten metal. After tapping into the ladle, the molten metal was poured into each of a metal mold for component analysis and a Y-shaped block (JIS B Test Specimen) molded through a $\mathrm{CO}_{2}$ method.

The name of test specimens prepared in this experiment and used raw material quantities are shown in Table 1 , and the shape of used pellets is shown in Fig. 1 respectively.

\section{Results and Discussions}

\subsection{Chemical composition of used pellets}

Before the melting experiment, for the purpose of investigating the chemical composition of pellets, $25 \mathrm{~g}$ of pellets shown in Fig. 1 were sampled and a test specimen shown in 
Table 1 Test specimens and used quantity of raw materials.

\begin{tabular}{lccc}
\hline Test specimens & Pig iron & $\begin{array}{c}\text { Pellet } \\
\text { material }\end{array}$ & $\begin{array}{c}\text { Component } \\
\text { adjustment* }\end{array}$ \\
\hline $\begin{array}{l}\text { Standard molten } \\
\text { metal }\end{array}$ & 9.0 & 0 & 0.350 \\
\hline Blending 10\% & 8.1 & 0.9 & 0.394 \\
\hline Blending 20\% & 7.2 & 1.8 & 0.436 \\
\hline Blending 40\% & 5.4 & 3.6 & 0.523 \\
\hline Blending 60\% & 3.6 & 5.4 & 0.608 \\
\hline Blending 100\% & 0 & 9.0 & 0.781
\end{tabular}

*Mainly the addition of electrolytic iron, carburizing material, electrolytic $\mathrm{Mn}$ and $\mathrm{Fe}-75 \% \mathrm{Si}$ alloy.

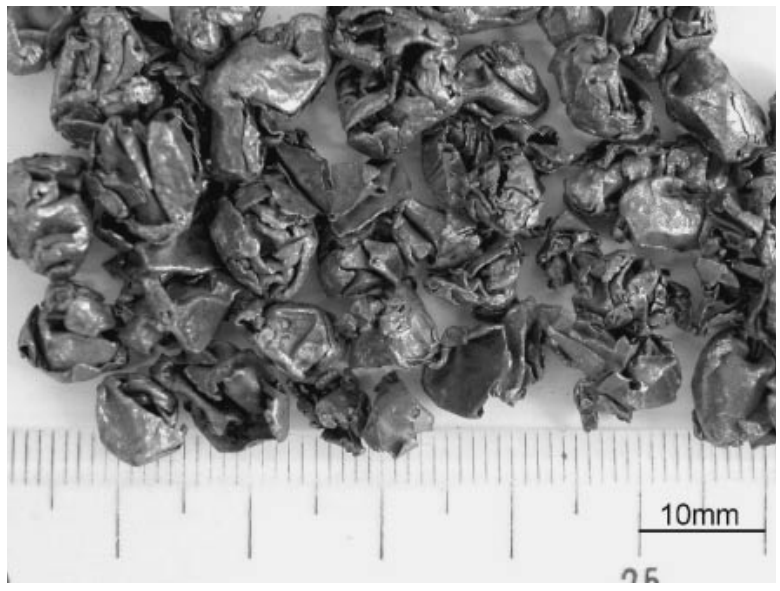

Fig. 1 Shape of steel can pellets.

Table 2 Chemical composition of steel can pellets.

\begin{tabular}{|c|c|c|c|c|c|c|c|c|c|c|c|}
\hline & & & & & & & & & & & hass\%) \\
\hline $\mathrm{C}$ & $\mathrm{Si}$ & $\mathrm{Mn}$ & $\mathrm{P}$ & $\mathrm{S}$ & $\mathrm{Ni}$ & $\mathrm{Cr}$ & $\mathrm{Cu}$ & $\mathrm{Al}$ & $\mathrm{Ti}$ & V & $\mathrm{Sn}$ \\
\hline 0.032 & 0.015 & 0.23 & 0.016 & 0.012 & 0.018 & 0.048 & 0.016 & 1.16 & 0.016 & 0.004 & 0.046 \\
\hline
\end{tabular}

${ }^{*} \mathrm{~Pb}<0.001$ mass $\%, \mathrm{Zn}<0.0015$ mass $\%$.

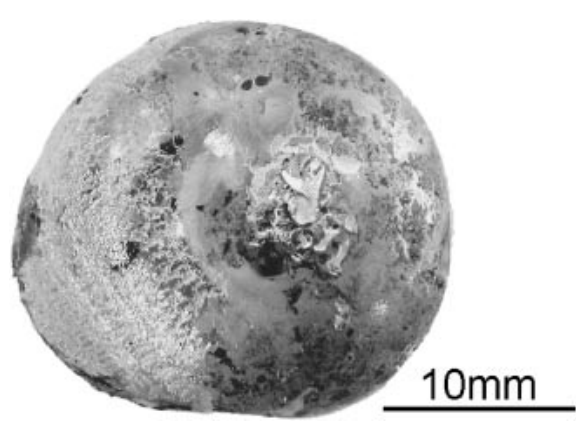

Fig. 2 Shape of a specimen after arc melting.

Fig. 2 was prepared through arc melting in an Ar gas atmosphere. The results of the spark discharge emission spectral analysis of the test specimen are shown in Table 2. Compared with iron scraps used in foundries, a comparatively large quantity of $\mathrm{Al}$ is detected. In addition, $\mathrm{Cr}$ and $\mathrm{Sn}$ are detected even in a small quantity. Mn content is in the same range as common iron scraps. The content of Al-Mn alloy used in the can's cap part of a steel can is approximately
5 mass $\%$ of the whole can body. ${ }^{2)}$ Judging from this ratio, in pellets used in this experiment, most of component Al-Mg alloy was supposedly removed, but still a little quantity remained.

It is inferred that the entry of $\mathrm{Cr}$ was from tin-free steel plates and that the entry of Sn was from tinned steel plates. In addition, $\mathrm{Cr}$ was also contained in the $\mathrm{Al}-\mathrm{Mg}$ alloy that had not been removed.

\subsection{Chemical composition of test specimens}

The results of the spark discharge emission spectral analysis of the test specimens prepared by rapidly cooling in a metal mold for changing to white pig-iron state are shown in Table 3.

The elements that show an increasing trend with an increase in the blending ratio of pellets (hereinafter, referred to as blending ratio) are $\mathrm{Al}, \mathrm{Cr}, \mathrm{Cu}, \mathrm{Ti}$ and $\mathrm{Sn}$. This is the reasonable trend that can be judged from the chemical composition of pellets. However, since Al content in the specimen in blending ratio of $100 \%$ decreased compared with $\mathrm{Al}$ content in pellets, part of $\mathrm{Al}$ must has been removed as slag while melting.

Table 3 Chemical composition of cast specimens.

(mass\%)

\begin{tabular}{|c|c|c|c|c|c|c|c|c|c|c|c|c|c|}
\hline & & & & & & & & & & & & & 1ass $\%$ \\
\hline $\begin{array}{c}\text { Test } \\
\text { specimens }\end{array}$ & $\mathrm{C}$ & $\mathrm{Si}$ & $\mathrm{Mn}$ & $\mathrm{P}$ & $\mathrm{S}$ & $\mathrm{Ni}$ & $\mathrm{Cr}$ & $\mathrm{Cu}$ & $\mathrm{Al}$ & $\mathrm{Ti}$ & V & $\mathrm{Sn}$ & $\mathrm{Mg}$ \\
\hline Standard metal & 3.82 & 2.38 & 0.27 & 0.028 & 0.007 & 0.016 & 0.024 & 0.004 & 0.02 & 0.008 & 0.005 & 0.003 & 0.044 \\
\hline Blending $10 \%$ & 3.55 & 2.45 & 0.27 & 0.025 & 0.006 & 0.015 & 0.025 & 0.005 & 0.04 & 0.008 & 0.004 & 0.007 & 0.046 \\
\hline Blending $20 \%$ & 3.72 & 2.32 & 0.25 & 0.026 & 0.010 & 0.017 & 0.029 & 0.006 & 0.11 & 0.007 & 0.004 & 0.010 & 0.046 \\
\hline Blending $40 \%$ & 3.57 & 2.42 & 0.28 & 0.019 & 0.008 & 0.017 & 0.034 & 0.009 & 0.20 & 0.009 & 0.003 & 0.018 & 0.041 \\
\hline Blending $100 \%$ & 3.08 & 2.74 & 0.24 & 0.022 & 0.006 & 0.016 & 0.042 & 0.012 & 0.40 & 0.014 & 0.002 & 0.033 & 0.056 \\
\hline
\end{tabular}

${ }^{*}$ All the specimens show $\mathrm{Pb}<0.001$ mass $\%$ and $\mathrm{Zn}<0.0015$ mass $\%$. 
Table 4 Mechanical properties of test specimens.

\begin{tabular}{|c|c|c|c|c|}
\hline Test specimens & $\begin{array}{c}0.2 \% \text { Proof stress } \\
\sigma_{0.2}(\mathrm{MPa})\end{array}$ & $\begin{array}{c}\text { Tensile strength } \\
\sigma(\mathrm{MPa})\end{array}$ & $\begin{array}{c}\text { Elongation } \\
\delta(\%)\end{array}$ & $\begin{array}{c}\text { Brinell hardness } \\
\text { (HBS 10/3000) }\end{array}$ \\
\hline Standard specimen & 286 & 440 & 24.8 & 146 \\
\hline Blending 20\% & 289 & 447 & 24.3 & 146 \\
\hline Blending $40 \%$ & 343 & 553 & 14.2 & 174 \\
\hline Blending $100 \%$ & 474 & 672 & 4.3 & 241 \\
\hline
\end{tabular}

In addition, $\mathrm{Cr}, \mathrm{Cu}$ and $\mathrm{Ti}$ are contained in the $\mathrm{Al}-\mathrm{Mg}$ alloy. For this reason, these elements are highly probable to enter from can's cap part made of the Al-Mg alloy that remained without being removed.

In addition, the decreasing trend of $\mathrm{P}$ and $\mathrm{S}$ following an increase in blending ratio may have been affected by an increase in the addition of pellets with low $\mathrm{P}$ and $\mathrm{S}$ contents. On the other hand, Table 3 shows that the specimen in blending ratio of $100 \%$ results in difficulty in carburizing.

On the other hand, according to making the blending ratio increase, the trend which $\mathrm{Si}$ and $\mathrm{Mg}$ contents increase is approved after adjusting the chemical composition of molten metal. Because $\mathrm{Al}$ contained in the pellets is removed as slug while melting the pellets, it is considered that the amount of molten metal has decreased than the calculated amount.

\subsection{Mechanical properties of test specimens}

From the parallel part of $25 \mathrm{~mm}$ in thickness of the samples that were cast in the mold for tensile strength test (Y-shaped block), JIS No. 4 test specimens were prepared. The results of tensile strength test are shown in Table 4 . The results of Brinell hardness of the parts near the rupture in the specimens after tensile strength test are jointly shown.

With an increase in blending ratio, $0.2 \%$ proof stress $\left(\sigma_{0.2}\right)$ and tensile strength $(\sigma)$ tends to increase, and Brinell hardness $(H B)$ also shows the same tendency. In contrast, elongation $(\delta)$ tends to decrease.

However, in the melting of this experiment, it was impossible to fix the contents of $\mathrm{C}$ and $\mathrm{Si}$, which have large effects on cast iron properties, at consistent values. Then, the concept of Reifegrad (maturity) as a material property judging method for flake graphite cast iron was applied. According to the regression formula proposed by Ikawa, regarding the $\mathrm{Y}$-shaped $\mathrm{B}$ test pieces of $25 \mathrm{~mm}$ in thickness with equivalent hardness, standard $\sigma_{\mathrm{B}}$ and $\delta$ can be obtained from the following equations. ${ }^{3,4)}$

$$
\begin{aligned}
\sigma_{\mathrm{B}} & =47.1+2.7 H B \\
\text { In } \delta & =5.02-0.013 H B
\end{aligned}
$$

Here, $\sigma_{\mathrm{B}}$ : Standard tensile strength (MPa)

$\delta$ : Standard elongation $(\%)$

$H B$ : Measured value of brinnel hardness

In addition, the ratio of obtained values from the eqs. (1) and (2) and measured values are used as the Reifegrad of spheroidal graphite cast iron, and the evaluation similar to the Reifegrad of flake graphite cast iron is conducted. The calculation equations of Reifegrad are as follows:
Table 5 Reifegrad of tensile strength and elongation.

$(\%)$

\begin{tabular}{lcc}
\hline Test specimens & $\begin{array}{l}\text { Reifegrad } \\
\mathrm{RG}\left(\sigma_{\mathrm{B}}\right)\end{array}$ & $\begin{array}{l}\text { Reifegrad } \\
\mathrm{RG}(\delta)\end{array}$ \\
\hline Standard specimen & 110 & 109 \\
\hline Blending 10\% & 112 & 103 \\
\hline Blending 20\% & 112 & 107 \\
\hline Blending 40\% & 116 & 90 \\
\hline Blending 60\% & 114 & 112 \\
\hline Blending 100\% & 103 & 65 \\
\hline
\end{tabular}

$$
\begin{aligned}
\operatorname{RG}\left(\sigma_{\mathrm{B}}\right) & =100 \cdot \sigma_{\mathrm{t}} / \sigma_{\mathrm{B}} \\
\operatorname{RG}(\delta) & =100 \cdot \delta_{\mathrm{t}} / \delta
\end{aligned}
$$

Here, $\operatorname{RG}\left(\sigma_{\mathrm{B}}\right)$ : Reifegrad judged from tensile strength $(\%)$ $\mathrm{RG}(\delta)$ : Reifegrad judged from elongation (\%)

$\sigma_{\mathrm{t}}$ : Measured value of tensile strength $(\mathrm{MPa})$

$\delta_{\mathrm{t}}$ : Measured value of elongation $(\%)$

$\mathrm{RG}\left(\sigma_{\mathrm{B}}\right)$ and $\mathrm{RG}(\delta)$ calculated from the eqs. (3) and (4) using $\sigma, \delta$ and $H B$ obtained in this experiment are shown in Table 5. The criterion of judgment is that the value over $100 \%$ is considered to show an excellent material.

The values of $\mathrm{RG}\left(\sigma_{\mathrm{B}}\right)$ shows over $100 \%$ in all blending ratios, suggesting that they are mostly good materials. However, the value of $\operatorname{RG}(\delta)$ drastically drops in blending ratio of $100 \%$. This means that this material changed into the material with high hardness and low elongation. When the values of $\sigma_{0.2}, \sigma$ and $\delta$ of the specimen in blending ratio of $100 \%$ are compared with the Japanese standard (JIS), this specimen meets the standard of FCD600-3, which has mostly similar values $\left(\sigma_{0.2} \geqq 370 \mathrm{MPa}, \sigma \geqq 600 \mathrm{MPa}, \delta \geqq 3 \%\right)$. However, the $H B$ increased to 241 compared with the standard of 140-210, which suggests that the test specimen in blending ratio of $100 \%$ is difficult for use as a standard material.

On the other hand, the specimen in blending ratio of $40 \%$ shows the $\operatorname{RG}(\delta)$ of 90 . This means that this specimen does not elongate compared with the others. However, it meets the standard of the most commonly used material FCD450-10 $\quad\left(\sigma_{0.2} \geqq 280 \mathrm{MPa}, \quad \sigma \geqq 450 \mathrm{MPa}, \quad \delta \geqq 10 \%\right)$. In addition, the specimen in blending ratio of $60 \%$ shows the $\operatorname{RG}(\delta)$ of 112 . Therefore, the datum of the blending ratio $40 \%$ is considered within the fluctuation of melting experiment. 

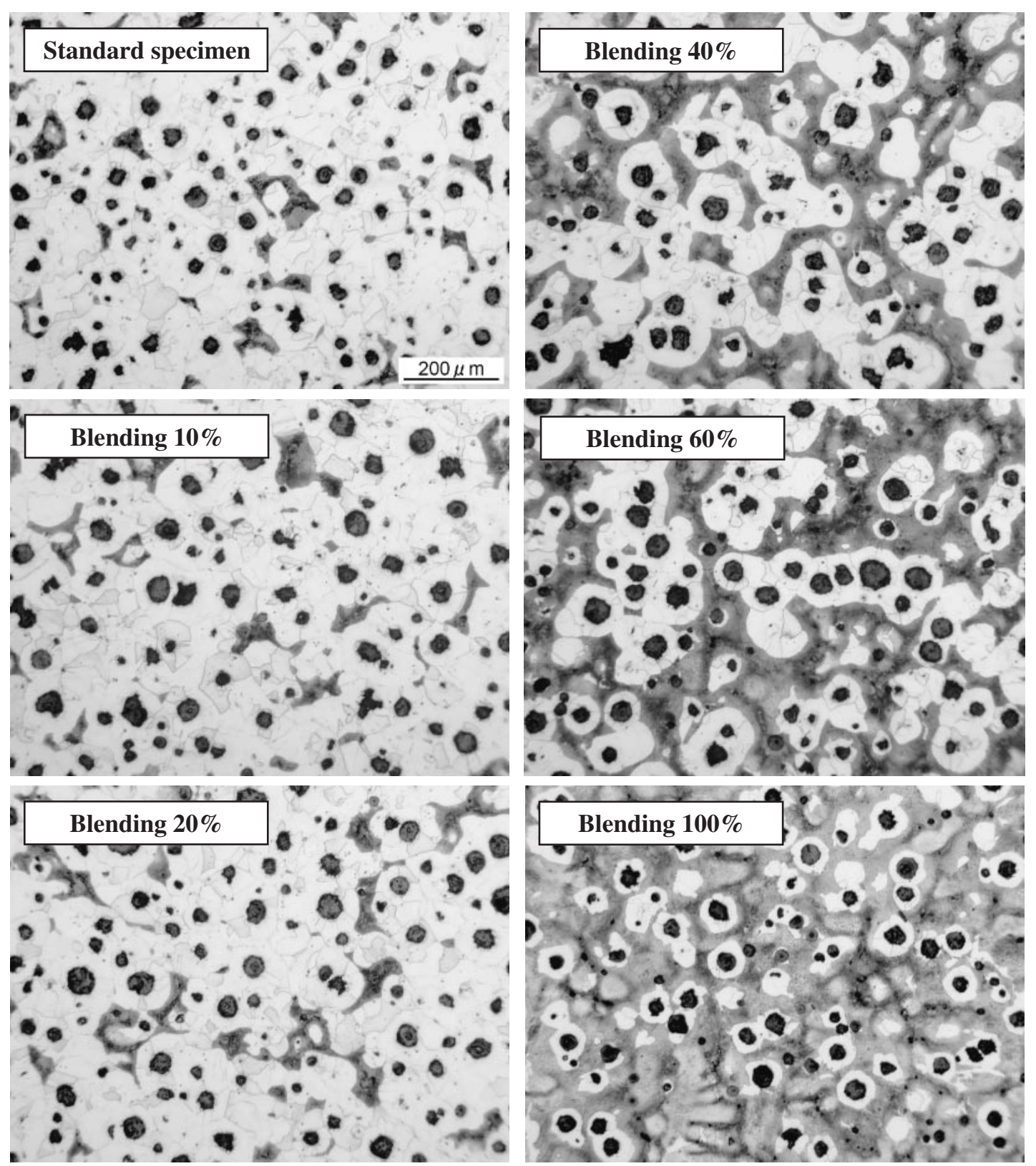

Fig. 3 Changes in microstructures depending on the blending ratio of pellets.

\subsection{Microstructure of test specimens}

The microstructures of the tensile strength test specimens made by casting pellets are shown in Fig. 3. The microstructures are shown at the parts near the rupture in the specimens after tensile strength test. In all the test specimens of various blending ratios, abnormality in graphite shape is not recognized. However, with an increase in blending ratio, progress in pearlite formation can be recognized. Changes in the microstructure appear as an increase in $\sigma, \sigma_{0.2}$ and $H B$. The cause for the progress of pearlite formation is considered to be an increase in $\mathrm{Cr}$ and Sn quantity following an increase in blending ratio. In addition, the solid solution hardening of $\mathrm{Al}$ into ferrite is also pointed out as the cause.

The results of measuring the ratio of graphite spheroidization (\%) and nodule counts (number $/ \mathrm{mm}^{2}$ ) using an image processor are shown in Table 6. The ratio of graphite spheroidization exceeds $80 \%$ in all the test specimens, showing mostly good results. The number of graphite
Table 6 Ratio of graphite spheroidization and nodule counts of test specimens.

\begin{tabular}{lcc}
\hline Test specimens & $\begin{array}{c}\text { Ratio of graphite } \\
\text { spheroidization }(\%)\end{array}$ & $\begin{array}{c}\text { Nodule counts } \\
\left(\text { number } / \mathrm{mm}^{2}\right)\end{array}$ \\
\hline Standard specimen & 90 & 153 \\
\hline Blending 10\% & 90 & 122 \\
\hline Blending 20\% & 88 & 136 \\
\hline Blending 40\% & 84 & 115 \\
\hline Blending 60\% & 90 & 126 \\
\hline Blending 100\% & 87 & 127 \\
\hline
\end{tabular}

${ }^{*}$ Grains with a circumscribed circle diameter over $15 \mu \mathrm{m}$ were chosen for measurement.

nodule tends to decrease in all the specimens compared with the standard specimen, but the differences in quantity are little. 


\subsection{Features of pellet material and utilization method}

The qualities of pellets are greatly affected by the conditions of steel can scraps accepted as a raw material. Here, the conditions mean the existences of impurities and the method of press treatment. For this reason, the qualities of pellets can sometimes be determined depending on suppliers. Although pellets used in this experiment contained $1.16 \%$ of $\mathrm{Al}$, the entry of $\mathrm{Al}$ may be suppressed by changing a supplier. However, the qualities equivalent to this pellet are considered usable as an additive such as a steel scrap which covers a Fe$\mathrm{Si}-\mathrm{Mg}$ alloy for treatments of graphite spheroidizing, even if some fluctuations in $\mathrm{Al}$ content exist.

On the other hand, in utilizing as steel scraps, the most practical method seems to be blending pellets into conventional steel scraps. It is recommended to repeat operational experiments with blending ratio of $10 \%$ or $20 \%$, in consideration of the control of return scraps in the foundry at first. It is safe to gradually increase blending ratio while checking slag generation quantities, effects on workability, and effects on the refractories of an inductive heating furnace.

\section{Conclusions}

In this research, the steel can pellet was melted as an iron source of cast iron, when spheroidal graphite cast iron was cast. It was confirmed that abnormality did not occur in cast iron qualities in the range of blending ratio up to $60 \%$, among test specimens that were prepared by changing blending ratio of steel can pellets.

Although spheroidal graphite cast iron was cast in this experiment, steel can pellets equivalent to this quality may be used as steel scraps for flake graphite cast iron in the range of blending ratio up to $60 \%$.
The obtained results in this study are as follows:

(1) Major elements contained in steel can pellets were Al, $\mathrm{Mn}, \mathrm{Cr}$ and $\mathrm{Sn}$, and especially Al was comparatively much contained. This Al may be originated from the Al-Mg alloy of steel can's cap part that could not be removed.

(2) Al contained in steel can pellets in a ratio of $1.16 \%$ remained in the cast test specimens after melting in a ratio of $0.4 \%$. The decrease may be due to the removal as the oxide of $\mathrm{Al}$ while melting.

(3) When only steel can pellet material was molten as an iron source, the carburization of molten metal was difficult. The cause may be due to the formation of the oxide film of $\mathrm{Al}$ on the surface of molten metal.

(4) In the cast test specimens made by increasing blending ratio, $0.2 \%$ proof stress, tensile strength, and brinnel hardness increased in proportion to the blending ratio. On the other hand, elongation decreased. According to evaluation based on the Reifegrad of spheroidal graphite cast iron, blending ratio up to $60 \%$ did not deteriorate material qualities.

(5) In all the test specimens made by casting through changing blending ratio, abnormality was not recognized in the shape of spheroidal graphite.

\section{REFERENCES}

1) Japan Steel Can Recycling Association: Steel can recycling annual report (2003) p. 3.

2) Japan Steel Can Recycling Association: Steel can recycling annual report (2003) p. 19.

3) K. Ikawa: IMONO 67 (1995) 56-61.

4) K. Ikawa: IMONO 68 (1996) 883-890. 